\title{
O USO DE ORGANIZADORES DE COMPRIMIDOS POR IDOSOS
}

\section{THE USE OF PILLS ORGANIZER BY ELDERLY}

\author{
Vanessa Cristina Libório ${ }^{1}$ \\ Ligia Maria S. De Medeiros ${ }^{2}$ \\ Sydney Fernandes De Freitas ${ }^{3}$ \\ (1) UERJ \\ vanessaliborio88@gmail.com \\ (2) UERJ \\ ligiamsm@yahoo.com.br
}

(3) UERJ

sydneydefreitas@gmail.com

Design de produto, embalagens, medicamentos.

O presente artigo apresenta uma breve análise dos organizadores de comprimidos disponíveis em drogarias físicas do município do Rio de Janeiro e investiga se suas características atendem o público consumidor de medicamentos, principalmente os idosos. Para isso, serão expostos alguns conceitos pertinentes ao tema, como o armazenamento de medicamentos e o perfil da terceira idade carioca.

\section{Product design, package, medicine.}

This article presents a brief analysis of the pills organizer available in physical drugstores in the city of Rio de Janeiro and investigates if its characteristics serve the consumers of drugs, especially the elderly. For this, will be exposed some concepts pertinent to the theme, such as the storage of medicines and the profile of the third age in Rio de Janeiro.

\section{Introdução}

Seguir corretamente um tratamento residencial com medicamentos pode ser uma tarefa difícil, principalmente quando o paciente possui algum comprometimento motor, visual e cognitivo, uma doença crônica, não é alfabetizado e/ ou utiliza polifarmácia, situações mais comuns entre idosos.
A complexidade do tratamento é mais um complicador do uso dos fármacos, pois se refere às instruções que devem ser seguidas pelo paciente, como cortar ou macerar o comprimido. Diante dessas dificuldades, idosos são estimulados a usar organizadores de comprimidos para administrar sua medicação de forma autônoma e satisfatória. Entretanto, esse artigo apresenta a hipótese que 


\section{$16^{\circ}$ \\ ERGODESIGN USIHC CINAHPA}

organizadores de comprimidos não estão adequados à realidade dos idosos brasileiros. Em um cenário mais pessimista, eles podem aumentar as chances de ocorrer um Problema Relacionado a Medicamentos (PRMs), como por exemplo: administração errada do medicamento, conservação inadequada, não cumprimento da prescrição e outros. A adesão do público ao uso desse produto ainda é baixa, como indica Lima (2012) na pesquisa realizada com pacientes cardíacos crônicos da cidade do Rio de Janeiro, a maioria mulheres entre 50 e 79 anos. Dos 35 entrevistados, apenas um utilizava os organizadores, 15 não conheciam esse produto e 19 conheciam mas não usavam porque achavam seu uso complicado, achavam que os comprimidos deviam ser organizados pelo nome do medicamento ou diziam ser mais um trabalho tirar o comprimido da embalagem original e depois do organizador (LIMA, 2012, p. 114). As entrevistas e questionários realizados por essa autora foram considerados referência para este trabalho, por isso não foram feitas novas pesquisas com idosos, apenas com geriatras.

A pesquisa tem como objetivo geral analisar os organizadores de comprimidos disponíveis nas drogarias físicas da zona norte da cidade do Rio de Janeiro. Para isso, o artigo tem como objetivos específicos apresentar as principais características e problemas dos organizadores, discutir sobre armazenamento de medicamentos, entrevistar geriatras e iniciar uma discussão sobre o uso de organizadores pelo público idoso. A justificativa para o tema escolhido está no crescimento da população idosa no Brasil e a importância da sua autonomia para a qualidade de vida desses indivíduos, com foco em um aspecto muito comum entre idosos: a utilização de medicamentos de uso contínuo.

\section{Os organizadores de comprimidos}

Os organizadores de comprimidos podem apresentar número variado de compartimentos e diversos formatos. Têm como objetivo facilitar o uso de medicamentos nas residências, proporcionando maior adesão ao tratamento, diminuição de erros e autocuidado entre os pacientes. Entretanto, eles podem trazer o resultado oposto. Para exemplificar $16^{\circ}$ Ergodesign - Congresso Internacional de Ergonomia e Usabilidade de Interfaces Humano Tecnológica: Produto, Informações Ambientes Construídos e Transporte

$16^{\circ}$ USIHC - Congresso Internacional de Ergonomia e Usabilidade de Interfaces Humano Computador

CINAHPA | 2017 - Congresso Internacional de Ambientes Hipermídia para Aprendizagem. algumas questões mencionadas nesse levantamento, será apresentada uma breve análise das principais características de organizadores de comprimidos vendidos em drogarias físicas da zona Norte da cidade do Rio de Janeiro, comprados no período de dezembro de 2015 a dezembro de 2016. Optou-se por esse meio de adquirir os produtos porque o número de idosos que acessa a Internet para fazer compras no Brasil ainda é limitado.

\subsection{Modelos de organizadores}

Os organizadores das figuras $1 \mathrm{a}$ e $1 \mathrm{~b}$ têm apenas sete compartimentos, um para cada dia da semana, enquanto o da figura 2 totaliza oito divisões. Como os comprimidos ficam juntos, é mais indicado para quem toma apenas um determinado medicamento por dia ou medicamentos diferentes na mesma hora do dia, pois assim o risco de confundir um comprimido com outro é nulo. Nos três produtos, os dias da semana são escritos em alto-relevo em português e em braile. Assim, eles atendem as necessidades de um deficiente visual, mas dificilmente atendem as de um idoso que precisa ler o dia da semana, pois o corpo da fonte é muito pequeno e as letras são da mesma cor do organizador. Por serem transparentes, os organizadores das figuras 1 b e 2 também não são indicados para medicamentos fotossensíveis.

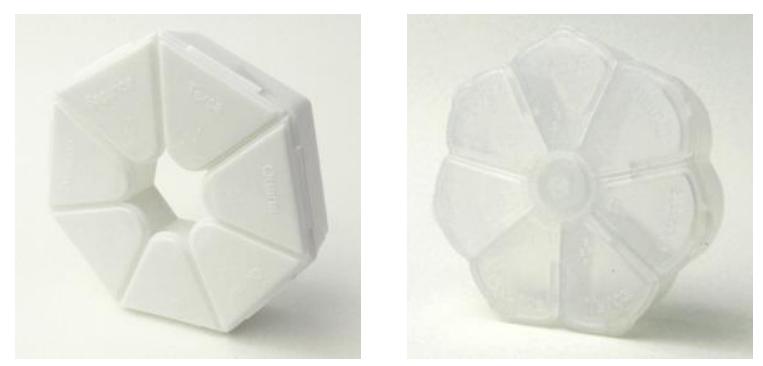

Figuras 1a e 1b-Organizadores de comprimidos. Fonte: Arquivo pessoal.

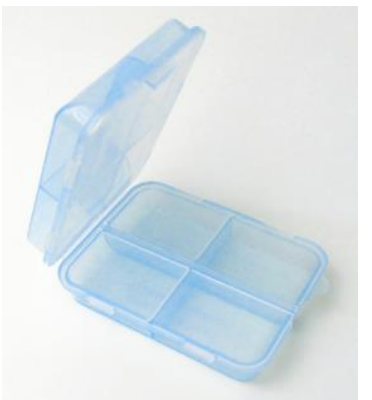

Figura 2 - Organizadores de comprimidos. Fonte:
Realização:

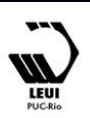




\section{$16^{\circ}$ \\ ERGODESIGN USIHC CINAHPA}

\section{Arquivo pessoal.}

O organizador da figura 3 também é transparente e possui quatorze compartimentos, dois para cada dia da semana: um para antes do meio-dia (representado pela sigla am), outro para após o meio-dia (representado pela sigla pm). Os dias da semana estão escritos em braile e impressos na cor branca (de forma abreviada). Porém, as tampas dos compartimentos formam uma peça única que sai com muita facilidade, o que pode fazer com que seu conteúdo seja perdido ou contaminado.

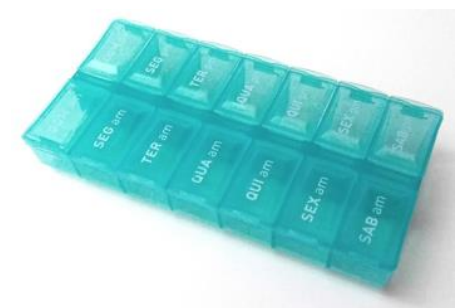

Figura 3 - Organizador de comprimidos transparente verde. Fonte: Arquivo pessoal.

Os organizadores das figuras $4 \mathrm{a}$ e $4 \mathrm{~b}$ têm formas diferentes, mas algumas semelhanças nos seus projetos. São transparentes, formados por um estojo inteiriço que guarda sete estojos menores, um para cada dia da semana, que são divididos em quatro compartimentos, um para cada período do dia. Os dias e períodos são escritos em braile e impressos na cor preta em português. No organizador da figura 4b, os dias são escritos de forma abreviada (mas seu entendimento é claro) e os estojos de cada dia saem com muita facilidade.
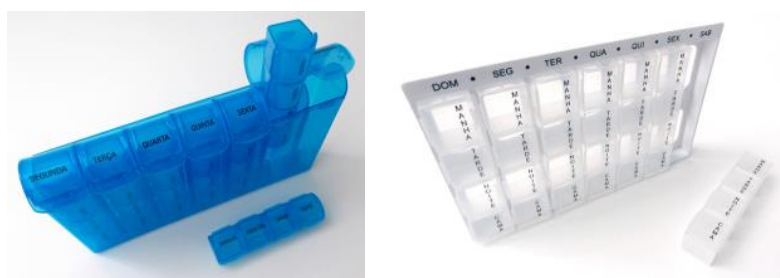

Figuras 4a e 4b - Organizadores de comprimidos. Fonte: Arquivo pessoal.

Alguns organizadores têm lâminas, para fracionar os comprimidos em doses menores (figura 5a). Existem também os cortadores de comprimidos, (figura 5b), com essa única função. $16^{\circ}$ Ergodesign - Congresso Internacional de Ergonomia e Usabilidade de Interfaces Humano Tecnológica: Produto, Informações Ambientes Construídos e Transporte

$16^{\circ}$ USIHC - Congresso Internacional de Ergonomia e Usabilidade de Interfaces Humano Computador

CINAHPA | 2017 - Congresso Internacional de Ambientes Hipermídia para Aprendizagem.
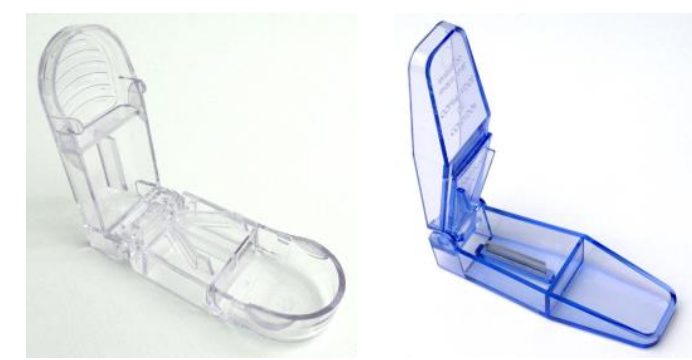

Figuras 5a e 5b - Organizador e cortador/ cortador de comprimidos. Fonte: Arquivo pessoal.

Para distribuir os comprimidos nos organizadores, é comum tirá-los das suas embalagens primárias originais. Entretanto, é preciso considerar os potenciais problemas decorrentes dessa prática. Borja-Oliveira (2013) apresenta os fatores que podem comprometer a estabilidade, eficácia e segurança dos medicamentos quando expostos ao ambiente. A autora relaciona as características dos produtos farmacêuticos a fatores ambientais (como temperatura, umidade e luz), a fatores associados ao próprio produto (como propriedades físicas e químicas), à forma farmacêutica e às propriedades da embalagem, sendo necessário manter os medicamentos dentro das condições ideais para garantir sua qualidade. Por exemplo, quando o armazenamento e transporte são modificados, a data da validade também pode sofrer alterações. Medicamentos fotossensíveis (sensíveis à luz) e higroscópicos (sensíveis à umidade do ar) também devem ser mantidos nas embalagens originais especiais devido às suas especificidades. Além disso, os medicamentos devem ser tirados da embalagem original apenas ao ser administrado pelo usuário, principalmente no caso daqueles que se desintegram na boca e que não devem entrar em contato repetitivo com a pele. Para evitar os problemas mencionados quando se utiliza organizadores, Borja-Oliveira (2013, p.125) sugere recortar a cartela do medicamento individualmente e usar "um organizador cujo espaço do compartimento permita o armazenamento do recorte da cartela". Porém, como complementa a autora, "esse cuidado não previne o problema da identificação do medicamento, uma vez que as embalagens informam nome do fármaco, concentração, lote, prazo de validade, etc.” (BORJA-OLIVEIRA, 2013, p.125). Sem essas informações, "eleva as chances de o usuário consumir um produto vencido e de confundilo com outro medicamento ou outra dosagem" 


\section{$16^{\circ}$ \\ ERGODESIGN USIHC CINAHPA}

(BORJA-OLIVEIRA, 2013, p.125).

Usar organizadores é oportuno se o medicamento vier em embalagens primárias fracionáveis, que permitem a divisão das cartelas. Assim, os comprimidos podem ser distribuídos individualmente nos organizadores ainda dentro da sua embalagem original, evitando: 1) riscos de contaminação ao entrar em contato com o meio externo e 2) perda de informações sobre o produto, pois elas são escritas mesmo na menor fração da embalagem. Entretanto, como observa BorjaOliveira (2013, p.125): "o espaço restrito do verso de cada unidade de comprimido ou cápsula requer o uso de letras muito pequenas, o que dificultaria a visualização das informações ali dispostas, sobretudo por idosos". Ainda, não são todos os medicamentos que podem ser encontrados em embalagens primárias fracionáveis, pois a RDC $\mathrm{n}$. 80/2006 determina que o fracionamento não se aplica a embalagens de medicamentos e substâncias sujeitos ao controle especial.

\section{Armazenamento de medicamentos}

Outro problema dos organizadores refere-se ao armazenamento dos medicamentos. É recomendado proteger o produto do calor e da umidade excessivos. Muitas vezes os usuários levam os organizadores em bolsos, bolsas e dentro de automóveis, onde a temperatura e umidade do ambiente são ainda maiores (BORJA-OLIVEIRA, 2013, p.125). Organizadores transparentes também são considerados uma forma de armazenamento inadequado (MARGONATO et al., 2008), pois crianças podem ver seu conteúdo e confundir com balas. Além de visualizar os medicamentos, uma criança pode conseguir acessá-los de uma forma mais fácil do que se estivessem guardados em sua embalagem original. Em alguns casos, o próprio organizador pode chamar atenção das crianças por ter uma forma fantasia, como no exemplo da figura 6. Diante da possibilidade deste organizador ser identificado erroneamente como um artigo para crianças, consta na sua embalagem o seguinte aviso: "Isto não é um brinquedo". $16^{\circ}$ Ergodesign - Congresso Internacional de Ergonomia e Usabilidade de Interfaces Humano Tecnológica: Produto, Informações Ambientes Construídos e Transporte

$16^{\circ}$ USIHC - Congresso Internacional de Ergonomia e Usabilidade de Interfaces Humano Computador

CINAHPA | 2017 - Congresso Internacional de Ambientes Hipermídia para Aprendizagem.
Figura 6 - Organizador de comprimidos semelhante a
um teclado de computador. Fonte: Arquivo pessoal.

Independente de o medicamento ser mantido na embalagem original ou em organizadores, é preciso estar atento ao seu armazenamento, visto que ainda é o maior agente causador de intoxicação acidental de crianças no Brasil. A seguir, serão apresentadas algumas pesquisas para esclarecer qual o critério para o armazenamento de medicamentos ser classificado como (in)correto e (in)adequado.

\subsection{Armazenamento (in)adequado $e$ (in)seguro de medicamentos}

Quando se refere a intoxicações de crianças por medicamentos em residências, uma das causas mais comuns é guardar os produtos farmacêuticos em lugares inadequados. Entretanto, pesquisadores usam denominações e parâmetros distintos para classificar esses locais. Para Margonato et al. (2008), os critérios para classificar $\mathrm{o}$ armazenamento como inadequado são: guardar o medicamento em local inferior a $1,5 \mathrm{~m}$ de altura; em local visível a crianças; e/ ou em recipiente sem tampa ou com tampa de material transparente. Porém, segundo Mastroianni et al. (2012), as condições de armazenamento podem ser classificadas como seguras/inseguras e adequadas/ inadequadas. Os locais seguros são aqueles que os medicamentos estavam fora do alcance de crianças; adequados são aqueles que não estavam expostos à luz, calor, umidade, sujeira ou próximos a animais, ralos, produtos de higiene, cosméticos e domissanitários. Já um levantamento realizado por Schenkel et al. (2005), identificou três erros relativos aos locais de armazenamento: exposição ao calor e umidade, exposição à luz e ao alcance de crianças (locais não chaveados).

\section{Entrevistas com geriatras}

Para levantar dados sobre o uso de medicamentos e organizadores por idosos, Libório e Freitas (2016) 


\section{$16^{\circ}$ \\ ERGODESIGN USIHC CINAHPA}

realizaram entrevistas semiestruturadas, entre os dias 11 de maio de 2016 e 08 de junho de 2016, com sete médicas geriatras da cidade do Rio de Janeiro, de forma a obter informações que ainda não estão disponíveis em fontes documentais com profissionais que têm amplo conhecimento da área. Das sete geriatras, quatro atendem em diferentes consultórios particulares, e três são da rede pública e trabalham em um mesmo hospital e ambulatório da rede municipal. O resultado da análise das respostas será apresentado a seguir.

\subsection{Perfil dos idosos}

O perfil dos idosos atendidos varia conforme o local de atendimento. Na rede pública, o perfil tende a ser mais homogêneo, com algumas diferenças entre os idosos atendidos no hospital e no ambulatório. No hospital municipal, são atendidos muitos idosos fragilizados, pois possuem demência, desnutrição, muitas vezes não estão acompanhados da família e não frequentaram a escola. No ambulatório municipal, os idosos são mais autônomos, porém, também estão fragilizados. Eles possuem média de estudo de quatro anos e a família geralmente os acompanha nas consultas médicas. Nos consultórios particulares, o público é mais heterogêneo. Uma das geriatras atribuiu essa diversidade de perfil ao convênio do consultório com os planos de saúde. Outra citou os convênios e a dependência dos planos de saúde dos filhos como fatores responsáveis pela maioria dos atendidos ser de renda mais baixa. Das quatro médicas da rede particular, uma atende nos bairros de Copacabana, na zona sul da cidade do Rio de Janeiro, e na Tijuca, zona norte da mesma cidade. No seu consultório na zona sul, os idosos possuem, em média, ensino superior. Já os atendidos na zona norte possuem entre o ensino fundamental e ensino médio. Uma das geriatras relatou que a maioria dos idosos atendidos por ela possui baixa escolaridade, enquanto outra relatou que a maioria possui ensino médio. Ambas, porém, concordaram em dizer que apenas uma minoria possui ensino superior. A última entrevistada disse que seu público possui, em média, o ensino médio.

\subsection{Polifarmácia}

$16^{\circ}$ Ergodesign - Congresso Internacional de Ergonomia e Usabilidade de Interfaces Humano Tecnológica: Produto, Informações Ambientes Construídos e Transporte

$16^{\circ}$ USIHC - Congresso Internacional de Ergonomia e Usabilidade de Interfaces Humano Computador

CINAHPA | 2017 - Congresso Internacional de Ambientes Hipermídia para Aprendizagem.
A polifarmácia é muito comum entre idosos. Todas as geriatras mencionaram essa questão em algum momento da entrevista, sendo que três citaram a quantidade de medicamentos ingeridos como uma queixa frequente dos idosos. Uma delas acrescentou que os pacientes precisam de ajuda quando administram muitos medicamentos. As geriatras da rede pública acrescentaram outro aspecto importante da polifarmácia: quando idosos menos instruídos precisam tomar três ou mais medicamentos, eles têm medo de trocá-los e tomar o errado. Então, para evitar cometer erros, eles preferem não aderir ao tratamento medicamentoso.

\subsection{Forma farmacêutica dos medicamentos}

Para três geriatras, os comprimidos continuam sendo a principal forma farmacêutica, e os medicamentos líquidos são indicados apenas para os idosos mais fragilizados e com distúrbio da deglutição. Uma delas disse que, dependendo do idoso, é preciso macerar o comprimido, enquanto outra disse que às vezes é preciso dividir o comprimido. Já para outras três, a preferência é por medicação líquida. Uma delas acrescentou que, como são poucos os medicamentos nessa forma farmacêutica, são prescritos comprimidos, que devem ser macerados caso o paciente precise. Para a última entrevistada, a forma farmacêutica prescrita para idosos e outras faixas etárias é igual, só o que muda é a dosagem.

\subsection{Fracionamento dos comprimidos}

Em muitos casos, é preciso fracionar o comprimido para diminuir a dose do medicamento devido a problemas no funcionamento dos rins e do fígado do idoso. O tamanho dos comprimidos também foi citado duas vezes como um problema comum. Uma geriatra indica que, quando o comprimido é muito grande, também é preciso fracioná-lo (ou macerá-lo), para facilitar a sua ingestão. Porém, os comprimidos nem sempre são próprios para serem fracionados ou macerados.

\subsection{Nome dos medicamentos}

Quatro geriatras disseram que é frequente os idosos não lembrarem o nome da medicação em uso por 


\section{$16^{\circ}$ \\ ERGODESIGN USIHC CINAHPA}

eles. As três geriatras da rede pública municipal e uma da rede particular relataram que os idosos identificam os medicamentos pela cor e formato da embalagem e dos comprimidos, e não pelo seu nome. Diante dessa situação, é cobrado dos idosos que eles decorem os nomes de seus medicamentos, para manutenção do autocuidado. Quando o idoso usa os organizadores, geralmente é a família que organiza os comprimidos para ele. Esse hábito leva o idoso a desconhecer os nomes dos seus medicamentos e, consequentemente, a perder o controle do seu próprio cuidado. Por isso, uma geriatra da rede particular enfatizou que, quando o idoso usa organizadores, é preciso manter o nome do medicamento em algum lugar do organizador e lembrar constantemente $o$ nome do medicamento. Caso contrário, ele perde sua autonomia, pois se torna cada vez mais dependente da família para gerenciar seu tratamento.

\subsection{Organizadores de comprimidos}

Para uma das médicas, o principal problema é o idoso distribuir os comprimidos nos organizadores, além de estar atento aos dias certos de tomar o medicamento. Uma segunda falou que os organizadores podem confundir o idoso e levá-lo a errar o horário ou a própria medicação, por isso os produtos devem ser adotados de acordo com o paciente. Duas relataram que os organizadores são usados por idosos com um leve prejuízo de memória para facilitar a adesão ao tratamento e proporcionar certa independência. Para ambas, geralmente é a família que organiza os comprimidos, entretanto, uma delas disse que, com o tempo e o estímulo dos parentes, os idosos devem passar a organizar os próprios medicamentos, embora precisem de supervisão. Além dos idosos que possuem algum prejuízo de memória, os organizadores são muito usados por idosos que moram sozinhos ou com outro idoso. Foi dito também que o indivíduo deve ter boa cognição e certo grau de instrução para entender os organizadores, além de ter certeza das prescrições. Aquele com prejuízo cognitivo maior deve receber o comprimido na mão ou na boca. As geriatras da rede pública concordaram que, para utilizar organizadores, os idosos precisam ser alfabetizados, ter um grau de escolaridade mais alto, assim como precisam ter competência $16^{\circ}$ Ergodesign - Congresso Internacional de Ergonomia e Usabilidade de Interfaces Humano Tecnológica: Produto, Informações Ambientes Construídos e Transporte

$16^{\circ}$ USIHC - Congresso Internacional de Ergonomia e Usabilidade de Interfaces Humano Computador

CINAHPA | 2017 - Congresso Internacional de Ambientes Hipermídia para Aprendizagem. cognitiva, sendo descartado o uso de organizadores em qualquer estágio de demência. Como dito anteriormente, muitos idosos não decoram os nomes dos medicamentos, eles identificam os medicamentos pela cor e formato da embalagem e dos comprimidos. Os organizadores são mais uma informação para assimilar, por isso eles confundem os idosos, e não possuem o tamanho das letras e as cores adequadas para atender indivíduos com comprometimento visual. Por isso, grande parte dos idosos prefere as embalagens originais de medicamentos.

\section{Considerações Finais}

Cada idoso tem uma dinâmica de uso de medicamentos e características pessoais próprias. Por isso, um dos parâmetros principais para saber se o uso dos organizadores é válido ou não é autonomia. Se ela aumenta ou é mantida, é um indicador positivo para o produto, se a dependência aumenta, o organizador deve ser descartado. A autonomia é importante visto que ela é frequentemente associada à qualidade de vida da terceira idade. Por isso, deve-se avançar na oferta de produtos na área voltados para as necessidades dos diferentes perfis de idosos. Dessa forma, esse artigo sugere que sejam feitos estudos sobre a usabilidade dos organizadores de comprimidos e das embalagens de medicamentos, para contribuir com esse debate e oferecer qualidade de vida aos seus usuários.

\section{BIBLIOGRAFIA}

BORJA-OLIVEIRA, C. R. Organizadores e cortadores de comprimidos: riscos e restrições ao uso. Rev. de Saúde Pública, v. 47, n. 1, p. 123 127, 2013.

LIBÓRIO, V. C.; FREITAS, S. F. A administração da polifarmácia do idoso segundo geriatras. In: Anais do $2^{\circ}$ Simpósio de Pós-Graduação em Design da ESDI - SPGD 2016, Rio de Janeiro, p. 130-136, 2016.

LIMA, V. L. A. Comunicação na utilização de medicamentos por pacientes crônicos: uma abordagem ergonômica. 2012. 198 f. Tese. 


\section{$16^{\circ}$ \\ ERGODESIGN USIHC CINAHPA}

$16^{\circ}$ Ergodesign - Congresso Internacional de Ergonomia e Usabilidade de Interfaces Humano Tecnológica: Produto, Informações Ambientes Construídos e Transporte

$16^{\circ}$ USIHC - Congresso Internacional de Ergonomia e Usabilidade de Interfaces Humano Computador

CINAHPA | 2017 - Congresso Internacional de Ambientes Hipermídia para Aprendizagem.

(Doutorado em design) Departamento de Artes e Design, PUC-Rio, Rio de Janeiro, 2012.

MARGONATO, F. B.; THOMSON, Z.;

PAOLIELLO, M. M. B. Determinantes nas intoxicações medicamentosas agudas na zona urbana de um município do Sul do Brasil. Cad. Saúde Pública, Rio de Janeiro, v. 24, n. 2, p. 333341, fev, 2008.

MASTROIANNI, P. C.; ANDRADE, R. V.; GALDUROZ, J. C. F.; FARACHE FILHO, A. Acesso, segurança e uso de medicamentos por usuários. Revista Ciência em Extensão, v.8, n.2, p. 6-24, 2012.

SCHENKEL, E. P.; FERNÁNDES, L. C.; MENGUE, S. S. Como são armazenados os medicamentos nos domicílios? Acta

Farmaceutica Bonaerense, Buenos Aires, v. 24, n. 2, p. 266-70, 2005.

\section{Agradecimentos}

Às geriatras que generosamente concederam as entrevistas;

Ao Programa de Pós-Graduação em Design da ESDI/UERJ, onde essa pesquisa está sendo desenvolvida. 